UCRL-JC- 107158

PREPRINT

\title{
Evaluation of Charged-Particle Reactions for Fusion Applications
}

\author{
Roger M. White, David A. Resler, and \\ Stephen I. Warshaw \\ Lawrence Livermore National Laboratory \\ Livermore, CA
}

\section{Invited paper prepared for the Intemational Conference on Nuclear Data for Science and Technology Jülich, Federal Republic of Germany}

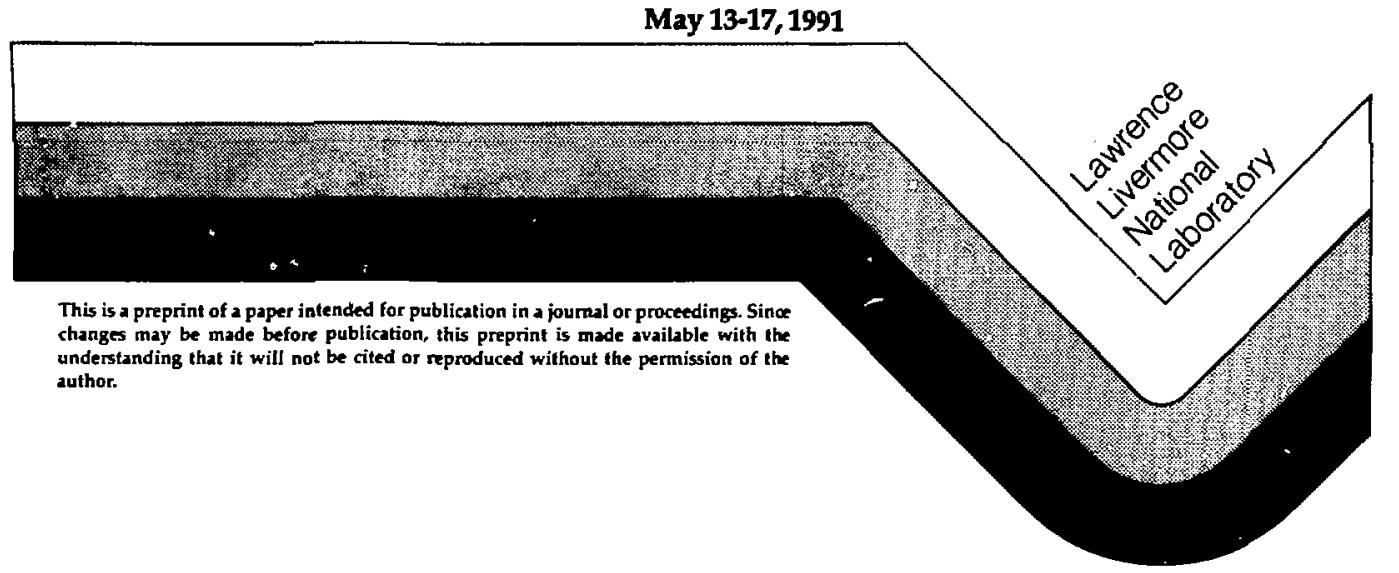

This is a preprint of a paper intended for publication in a joural or proceedings. Since changes may be made before publication, this preprint is made available with the understanding that it will not be cited or reproduced without the permission of the author. 

Roger M. White, David A. Resler, and Stephen I. Warshajy University of Califonia Lawrence Livermore National Laboratory

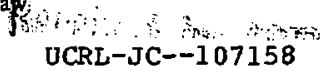
Livermore, CA 94550 U.S.A.
DE91 014135

\begin{abstract}
New evaluations of the total reaction cross secrions for ${ }^{2} \mathrm{H}(\mathrm{d}, \mathrm{n}){ }^{3} \mathrm{He},{ }^{2} \mathrm{H}(\mathrm{d}, \mathrm{p}){ }^{3} \mathrm{H},{ }^{3} \mathrm{H}(\mathrm{t}, 2 \mathrm{n}){ }^{4} \mathrm{He}$, ${ }^{3} \mathrm{H}(\mathrm{d}, n)^{4} \mathrm{He}$, and ${ }^{3} \mathrm{He}(\mathrm{d}, \mathrm{p})^{4} \mathrm{He}$ have been completed. These evaluations are oased on all known published data fros 1946 to 1990 and include over 1150 measired data points from 67 references. The pirpose of this work is to provide a consistent and well-documented set of cross sections for use in celculations relating to fusion energy research. A new thermonuclear data file, TDF, and a library of FORTRAN subprograms to read the file have been developed. Calculated from the new evaluations, the TDF file contains is imation on the Maxwellian-averaged reaction ntes as a function of renction and plesma temperanure nd the Maxwellian-averaged average energy of the inferacting purticles and reaction products. Routh.is are included that provide thermally-broadened spectral information for the secondary reaction products.
\end{abstract}

$\left[{ }^{2} \mathrm{H}(\mathrm{d}, \mathrm{n})^{3} \mathrm{He},{ }^{2} \mathrm{H}(\mathrm{d}, \mathrm{p})^{3} \mathrm{H},{ }^{3} \mathrm{H}(\mathrm{t}, 2 \mathrm{n}){ }^{4} \mathrm{He},{ }^{3} \mathrm{H}(\mathrm{d}, n)^{4} \mathrm{He},{ }^{3} \mathrm{He}(\mathrm{d}, \mathrm{p})^{4} \mathrm{He}\right.$ reactions, charged-particle evaluations, i sion teactions, fusion reactivities, Maxwellian-2veraged reaction rates, calculated emission spectra, astrophysical S-factors, R-matrix andyses]

\section{Introduction}

This work has been done to provide a consistent and well-documented set of evaluated cross sections from which processed information can be generated for use in fusion applications. An important part of this is to provide the user with a realistic assescment of the uncerthinties remaining in these reaction cross sections. We have developed a processed dara file which accurately represents the information needed in practical calculations. This paper contains onty the most briff summary of an extensive final repart to be produced later this year and is referenced here as LINL evaluation [91].

We have assessed and extracted total reaction cross sections as a function of eneray. The sources of experimental data were in the form of integrated cross sections, angular distributions of secondary particles, measurements at one angle multiplied by $4 x$ where the angular distribution is assumed or known to be isotropic, or, astrophysical S-factors-basically a quantity which is the cross section divided by the Coulomb penerrability and incideat energy. It is usually smoothly varying with energy and represents the nuelear par of the cross section. Some data sets were available only in graphical form and were scanned with a digitizing program written for this application to insure that no additional error (beyond that introduced by the draftsman) resulted. Integrated cross sections were obtained from measured angular distributions by convering them to center-of-mass values and using a least-squares fitting procedure to obtain Legendre polynomial coefficients actording to a consistent prescription.

\section{Cross section evaluations}

References and graphical symbols for the experimental data bases used in the five evaluated reaction cross sections are given in Fizs. 1, 4, 8, 10, and 14 and in the references section. Also included in these figures are the uncertainties (at the 95\% confiderce level) we place on the evaluations over the energy range of importance to fustion applications.

In Fig. 2, we show the two most recent measurements of the ${ }^{2} \mathrm{H}(\mathrm{d}, \mathrm{n})^{3} \mathrm{He}$ traction by Brown[90] and $\mathrm{I}-2 \mathrm{duss}[87]$ along with the older mensurement of Amold[54] fotted in terms of the estrophysical S-fuctor from $E_{d}=0$ to $0.2 \mathrm{MeV}$ (in all figurs the scale is the kinetic energy of the sident particle in the laboratory framel. The measureme its of Krauss[87] are separated into (b) and (m) because they were carried out at two different facilities. The measurements of Brown[90] are approximutely $8 \%$ higher than the previous messurements. In Fig. 3, in extrapolation of the S-factor from higher energies clearly fuvors the measurements of Brown[90]. Curnent knowledge of the struchure of "He indicates that the S-factor is smooth over the 400 keV range plotted in Fig. 3. Not shown in Fig. 3 are the data of Devidenko[57] becuuse of a shape difference and large error bars and the data of Chagnon[56] which are considerably different from the ouber measurements. As with the other reactions discussed below, data of some authors listed in Fig. 1 for the ${ }^{2} \mathrm{H}(\mathrm{d}, n)^{3} \mathrm{HE}$ reaction are aot shown because they are not in the energy range plotted in the figure.

In Fig. 5 , we show all the data for the ${ }^{2} \mathrm{H}(\mathrm{d}, \mathrm{p})^{3} \mathrm{H}$ reaction from $E_{d}=0$ to $0.2 \mathrm{MeV}$. The data are somewhat discrepant but an extrapolation of the S-factor from higher energies together with the dats of Brown[90] and Amold[54] and knowledge of the structure of "He give us confidence in the evaluation to $\pm 3 \%$. In Fig. 6 we show the high energy evaluation of the ${ }^{2} \mathrm{H}(\mathrm{d}, \mathrm{p})^{3} \mathrm{H}$ reaction as the $S$-factor ys. $E_{d}$. Plotted in this way, an extrapolation to 30 $\mathrm{MeV}$ is less difficult to make. Figure 7 shows the same datu plotted in terns of cross secrion vs. $E_{d}$.

The data base for the ${ }^{7} \mathrm{H}(\mathrm{t}, 2 \mathrm{n})^{4} \mathrm{He}$ reaction is more sparse as can be seen in Figs, 8 and 9. The S-factor vs. $E_{8}$ shows a clear indication of changing slope from $E_{l}=0$ to $0.4 \mathrm{MeV}$. The evaluation above $1 \mathrm{MeV}$ is heaviiy weighred in favor of the measurements of Govorov[62] and Jarmie[58]. Further details describing this evaluation will be given in the final repart.

The ${ }^{3} \mathrm{H}(\mathrm{d}, n){ }^{4} \mathrm{He}$ reaction evaluation shown in Fig. II is based on a single-level R-mutrix fit to all but three mensurements. The three daca sets not used are shown in $-1-$ 
- ${ }^{2} \mathrm{H}(\mathrm{d}, n)^{3} \mathrm{He}$ LLNL Evaluation References

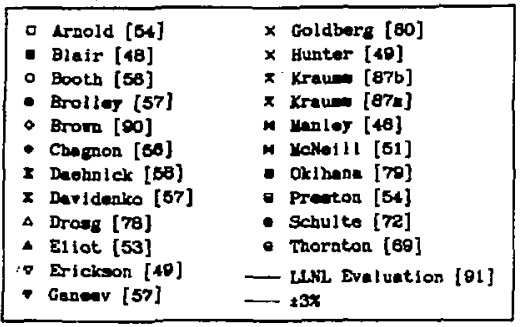

Fig. 1. References and plotting symbols used for the ${ }^{2} \mathrm{H}(\mathrm{d}, \mathrm{n})^{3} \mathrm{He}$ resction dath as shown in Figs, 2 and 3.

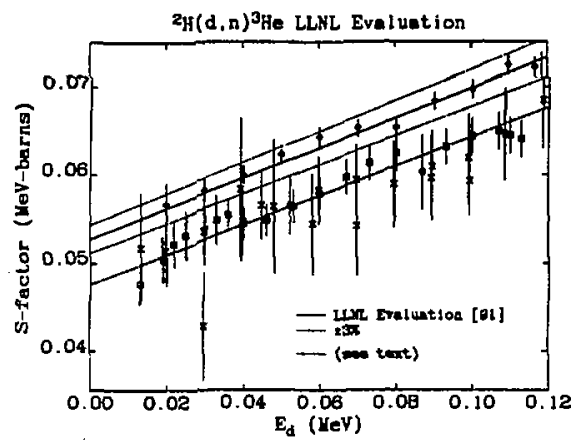

Fig. 2. The recent measurements of Brown[90] and Krauss[87] are plotted with the work of Amold[54] as the astrophysical S-factor vs. $E_{d}$ in the laboratory frame. The data of Brown[90] are approximately $8 \%$ higher than the previous measurements.

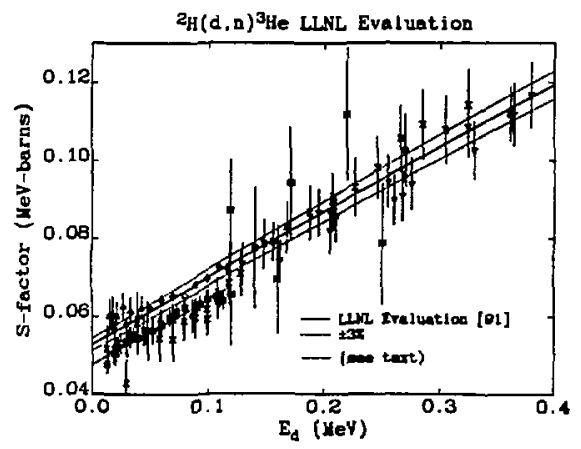

Fig. 3. The dashed line here and in Fig. 2 represents the most likely cvaluation in the energy range $E_{d}=0$ to $0.12 \mathrm{MeV}$ without the Brown[90] measurement and if to daca bad existed above $0.12 \mathrm{MeV}$. Not all date are plotied in this figure (see text).
${ }^{2} \mathrm{H}(\mathrm{d}, \mathrm{p})^{3} \mathrm{H}$ LLNL Evaluation References

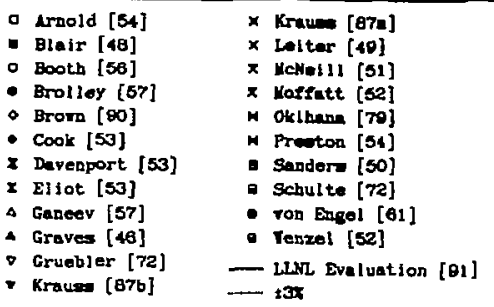

Fig. 4. References and plotting symbols used for the ${ }^{2} \mathrm{H}(\mathrm{d}, \mathrm{p})^{3} \mathrm{H}$ reaction data as shown in Figs. 5,6 , and 7.

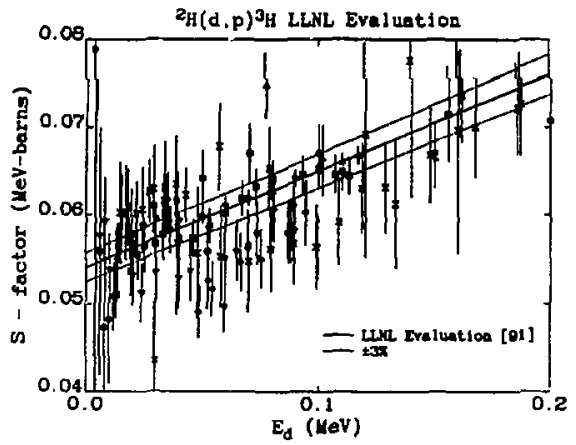

Fjg. 5. All ${ }^{2} H(d, p)^{3} H$ experimental data and the evaluation plotted as the S-factor vs. $E_{d}$ from 0 to $0.2 \mathrm{MeV}$.

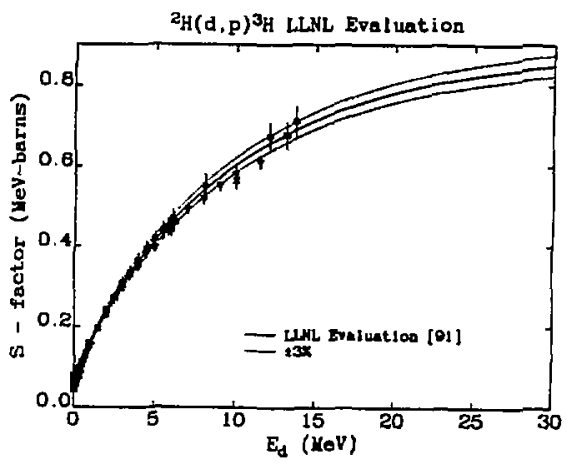

Fig. 6. Data and the evaluation of the high-energy portion of the ${ }^{2} \mathrm{H}(\mathrm{d}, \mathrm{p})^{3} \mathrm{H}$ reaction plotred in terms of the $\mathrm{S}$ factor v5. $E_{d}$ to show how the evaluation was carried out to $30 \mathrm{MeV}$. 


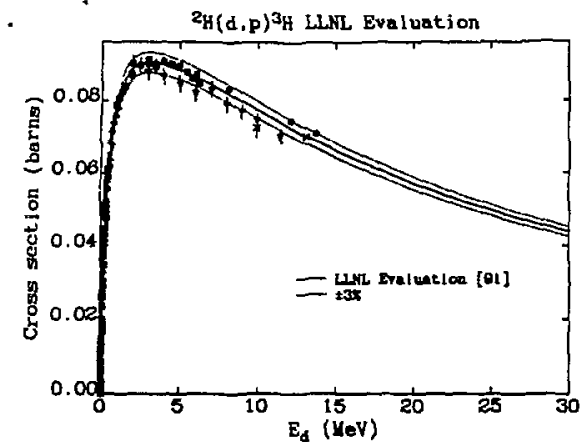

Fig. 7. Same as in Fig. 6 except plotted as cross section vs. $E_{d}$ to show how the cross section is extrupolated to $30 \mathrm{MeV}$.

Fig. :2 as ratios to the evaluation with the dashed lines serving to guide the eye. Numerous R-mutrix calculations were performed using many energy ranges and using various subsets of all the data. All of the results fall within the $\pm 2 \%$ indicated. The final evaluation is based upon allowing the normalization of each measurement to vary while simultaneously performing a least-squares fit with a single-level R-matrix caltulation. Showa in Fig. 11 are the measurements used in the R-matrix fit, the average percent error for each data set, and the percent change in the overall normalization for arriving at the best fit. We assumed that the overall normalization of the entire data base is roughly correct and therefore the nomalizations of the individual data sets were allowed to vary subject to the constraint that the average normalization was unity. The data plotted in Figs. 11 and 12 have been renormalized by the amount indicated in Fig. 11. In Fig. 13, we show the R-marrix analyses by Jarmie[84] and Brown[87] is ratios to the LLNL evaluation [91]. We also show the effect of not allowing the individual data sets to change in normalization. All of these results fall within $\pm 2 \%$ and indicate to us the uncertainty limils of this date base. Mone specific details of the R-matrix calculations and renormulization procedures will be presented in the final report.

Of the five reactions evaluated in this work, the measurements for the ${ }^{3} \mathrm{He}(\mathrm{d}, \mathrm{p})^{4} \mathrm{He}$ reaction (Fig, 15) are the moost discrepant. The absolute values differ by more than the experimenters' quoted enors. As shown in Fig. 16, except for the date sets of Bonner[52] and Jarvis[53] and the low-energy portion of the data sets of Cariton[30] and Kliucharev[56], the shapes are in good agreement For $E_{d}=0$ to $800 \mathrm{keV}$, the evaluation is based on a single-level R-matrix fit to all the available data except for those discussed above. Many R-matrix calculations were performed under a variety of conditions and the best fit was obtained by simulcaneously allowing the individual date set normulizations to vary. The normalizations of many data sets differ with one another by more than the quoted errors and it is not obvious which measurement is correct. Therefore, we assumed that, on the average, the overall normalization of all the measurements is correct and the individual data set normalizations should avernge to unity. In Fig. 17, we show the average percent error for each data set and the percent change in normalization for arriving at the best fit. The dat plorted are only thore points included in the fiting process and have been renormalized by the indicated amounts. We believe the evaluation to be good to no better than $\pm 8 \%$ in normalization even though we are certain that the shape of the ${ }^{3} \mathrm{He}(\mathrm{d}, \mathrm{p})^{4} \mathrm{He}$ reaction is known much bener.

\section{Applications File-TDF}

We have developed a thermonuclear data file, TDF, which is an ASCI file that contains thermonuclear reaction rates and spectral information on the outgoing particles as 2 function of plesma temperature. This file contains interpolatable data for all plasma temperatures from $100 \mathrm{eV}$ to $1 \mathrm{MeV}$. It is assurned tha the distribution of the reacting particles in the plasma is Mexwelling. Currently, TDF contains reaction rates and spectral information calculated

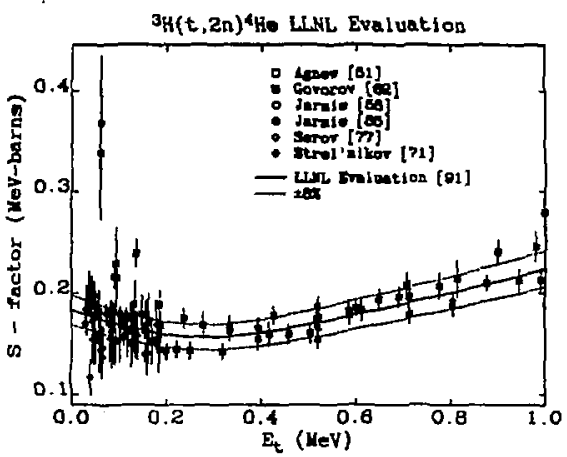

Fig. 8. Plot of all experimental date and evaluation of the ${ }^{3} \mathrm{H}(\hbar, 2 \mathrm{n})^{4} \mathrm{He}$ reaction from $E_{t}=0$ to $1.0 \mathrm{MeV}$. The change in slope of the evaluation between 0 and 0.5 $\mathrm{MeV}$ is independent of any pariar. Lar data set or of the evaluation techaiques we used on this deta base.

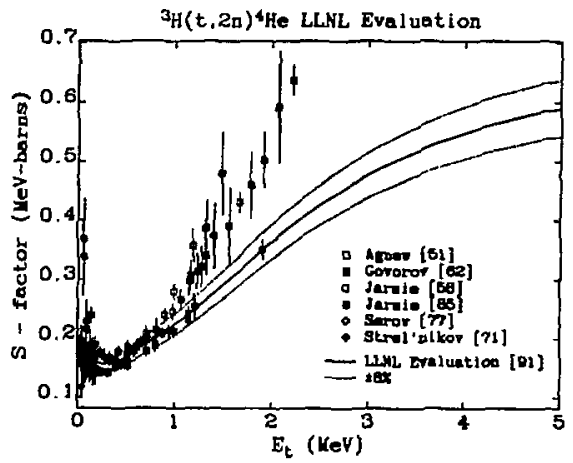

Fig. 9. Plot of the ${ }^{3} \mathrm{H}(t, 2 \mathrm{n})^{4} \mathrm{He}$ dati and extrapolation of the evaluation to higher energies in terms of the Sfactor vs. $E_{t}$. Further details describing this evaluation will be given in the final report described in the text. 
${ }^{3} \mathrm{H}(\mathrm{d}, \mathrm{n})^{4} \mathrm{He}$ LLNL Evaluation References

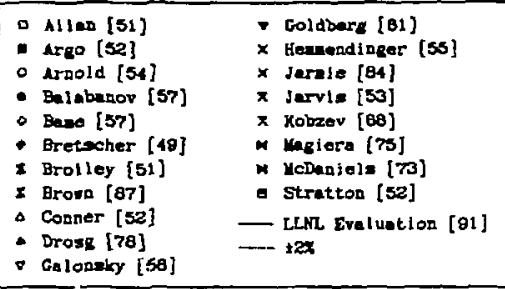

Fig. 10. References and plotting symbols used for the ${ }^{3} \mathrm{H}(\mathrm{d}, \mathrm{n}){ }^{4} \mathrm{He}$ reaction dan as shown in Figs. 11, 12, and 13.

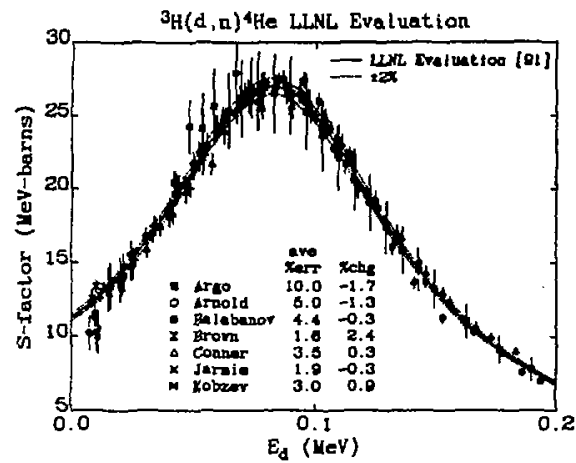

Fig. 11. Experimenal data and evaluation for the ${ }^{3} \mathrm{H}(\mathrm{d}, \mathrm{a})^{4} \mathrm{He}$ reaction in terms of the S-factor vs. $E_{d}$. The ave Goerr is the average total error of each data set. The \%ochg is the renormalization of each data set for the best R-matrix fit (see text).

from the five evaluated reactions diseussed in the previous section in units selectable by the user.

We have also developed a library of four subprograms written in FORTRAN77 for accessing TDF. The first subprogram is simply a reader and is called only once in an applications program prior to any call of the other three subprograms. The second subproperm renurs the value of the reactivity (Maxwellian-averaged reaction rate) given a reaction number and a plasma temperature. The thind subprogram returns the reactivity and the Maxwellian-averaged average energies of the two interacting particles and the reaction products given a reaction number and a plasma temperanore. The fourh subprogram is a spectrol lookup routine (SPECLU) which is slightly more complicated. This subprogram will return the energy of a recondery reaction particle and the value of the corresponding spectral shape function in the frame of a laboratory detector as a function of a real number, $R N$, between 0 and 1 . We show in Fig. 18 plots of the normalized spectral distributions vs. neutron emission energy for the ${ }^{3} \mathrm{H}(\mathrm{d}, \mathrm{n})^{4} \mathrm{He}$ reaction as temperatures of 5, 10,26, and $50 \mathrm{keV}$. These plots were generated by repeated calls to SPECLU for 1000 input RN's equally spaced between 0 and 1 . The filled

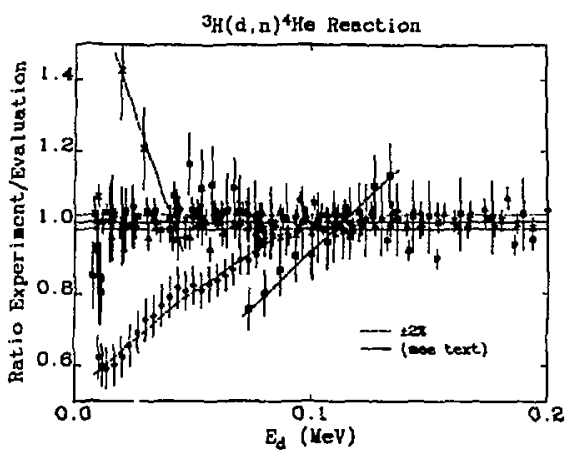

Fig. 12. Ratio of experimental data to evaluation for the ${ }^{3} \mathrm{H}(\mathrm{d}, \mathrm{n})^{4} \mathrm{He}$ reaction showing which data sets were excluded from the R-matrix fiting procedure.

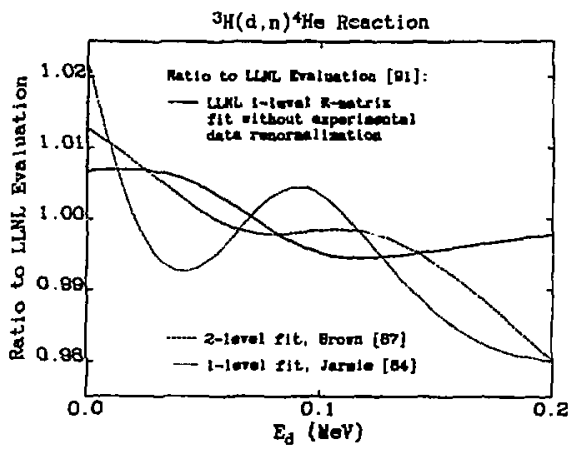

Fig. 13. Ratio comparisons of our R-matrix fit without data renormalization and the R-matrix fils of Jarmie[84] and Brown[87] to our evaluation of the ${ }^{3} \mathrm{H}(\mathrm{d}, \mathrm{n})^{4} \mathrm{He}$ cross section.

diamonds are the result of a CALL SPECLU as described above but for 2500 random numbers, $R N$, where the neutron energies are grouped into 50 bins. This gives one example of how this routine and TDF could be used in a Monte Carlo type calculation.

The calculations for the spectral information are carried out during the production of the TDF file so the file itself contains spectral dat which lend themselves to fast look-up techriques. Because this information is obtained from complex calculations using the more fundamental cross sections, considerable effor was put into the computational algorithms to insure accuracy first and then speed. The processing code which produces the TDF file and the subprograms which provide the interpolations and look-ups introduce errors at a level of not more than $0.1 \%$. The TDF file and the library of subprograms have been successfully uested on computers using three different operating systems and we consider them to be machineindependent. They will be available for public distribution laier this year. 
- $3_{\mathrm{He}}(\mathrm{d}, \mathrm{p})^{4} \mathrm{He}$ LLNL Evaluation References

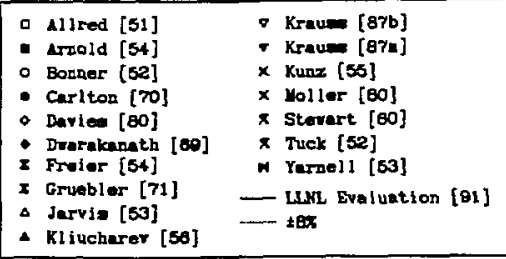

Fig. 14. References and plotting symbols used for the ${ }^{3} \mathrm{He}(d, p){ }^{4} \mathrm{He}$ reaction duta as shown in Figs. 15, 16 , and 17.

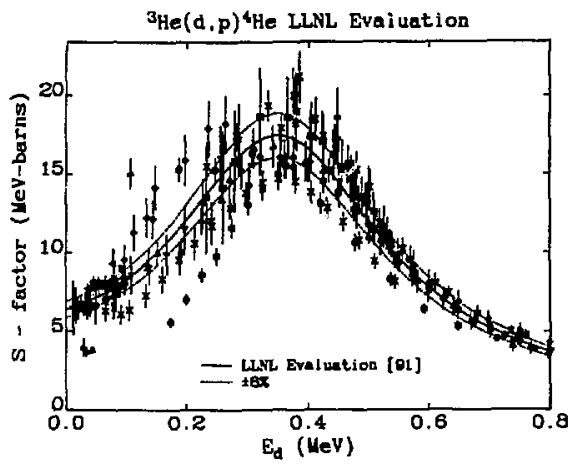

Fig. 15. Plot of all experimental data and evaluation of the ${ }^{3} \mathrm{He}(\mathrm{d}, \mathrm{p}){ }^{4} \mathrm{He}$ reaction in terms of the $S$-factor vs. $E_{d}$ from 0 to $0.8 \mathrm{MeV}$.

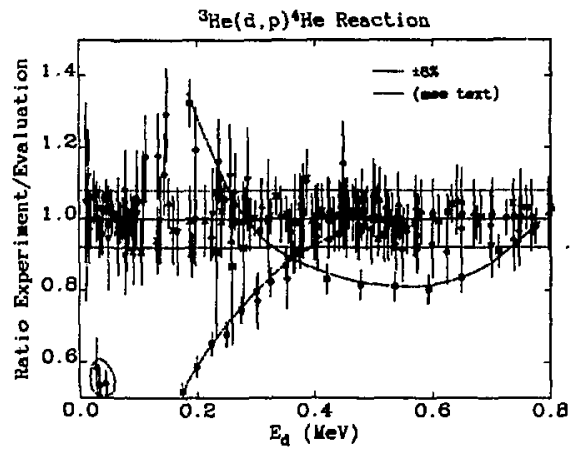

Fig. 16. Racio of experimental data to evaluation for the ${ }^{3} \mathrm{He}(\mathrm{d}, \mathrm{p})^{4} \mathrm{He}$ reaction showing which data sets were excluded from the R-marix fitting procedure.

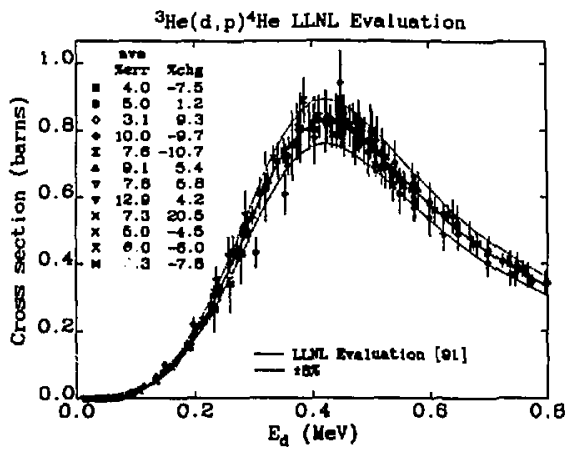

Fig. 17. Experimental dat and evaluation for the ${ }^{3} \mathrm{He}(d, p){ }^{4} \mathrm{He}$ reaction in terms of cross section vs. $E_{d}$. The numbers have the same mearing as described in Fig. 11.

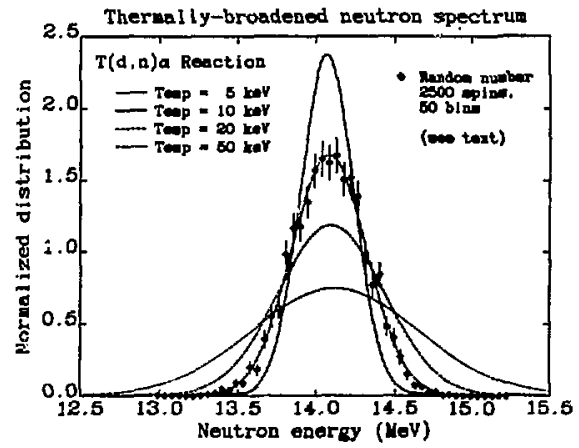

Fig. 18. Plot of the thermally-brosdened neutron spectrum for the ${ }^{3} \mathrm{H}(\mathrm{d}, \mathrm{n}){ }^{4} \mathrm{He}$ reaction for several plasma temperatures. The filled diamonds are described in the text. This information is obtained directly from TDF using the subprograms library.

\section{Conclusions}

We have given a brief overview of new evaluations of the most important charged-particle reaction cross sections needed for cursent fusion applications. We have also discussed a new applications file, based on these evaluations, which is machine-independent and provides the most importunt kinds of information necessary for fusion applications. This paper is intended to provide orly a brief summary of a more extensive report to be produced later this year.

Work performed under the auspices of the U.S. Department of Energy by the Lawrence Livermore National Laboratory under contract number W-7405-ENG-48. 
Agnew[51]

Allan[51]

Allen[58]

Allred[5i]

Argo[52]

Anold[54]

Balabanov[57]

Bume[57]

Bhir [48]

Bonner[52]

Booth[56]

Bretscher[49]

Brolley[51]

Brolkey[57]

Brown[87]

Brown[90]

Cariton[70]

Chatgon[56]

Conner[52]

Cook[53]

Dachnick[58]

Davenport[53]

Davidenko[57]

Davies[80]

Drosg[78]

Dwarakangh[69]

Eliot[53]

Erickson[49]

Freier[54]

Gakonsky[56]

Cancev[57]

Goldberg[60]

Goldberg[61]

Govorov[62]

Graves[46]

Grüebler[71]

Gñebler[72]

Hemmendin

Hunter[49]

Jamie[58]

Jarnic[84]

Jamie[85]

Jarvis[53]

Kliucharev[56]

Kobez[66]

Krauss[87]

Kunz[55]

Leiter[49]

Magiera[75]

Mariley[46]

McDanieis[73]

McNeill[51]

Moffau[52]

Moller[80]

Okinara[79]

Preston[54]

Sunders[50]

Schulte[72]

Serov[77]

Stewart 60 ]

Stration[52]

Strel'nikov[71]

Thorton[69]

Tuck (52]

vonEngle[61]

Wenzel[52]

Yamell[53]
H.M. Amew, W.T. Leland, H.V. Argo, R.W. Crews, A.H. Hemmendinger, W.E. Scoth, and R.F. Taschek, Phys. Rev. 84, 862 (1951).

D.L Allun and M.J. Poole, Proc. R. Soc. London, Ser. A 204, 488 (1951).

R.C. Allen and N. Jumic, Phys. Rev. 111, 1129 (1958).

J.C. Allied. Phyt. Rey. 84, 095 (1951).

H.V. Argo, R.F. Taschek, H.M. Apenew, A Hemmendinger, and W.T. Leland, Phys. Rev. 87, 612 (1952).

WR. Amold, J.A. Phillips, G.A. Stwyer, E.J. Stovall, Jr., and J.L. Tuck, Phys. Rev. 93, 483 (1954); Los Alamos

Scientific Laboracry Reports LA-1479 and LA-1481 (unpublished).

E.M. Balsbanow, I.la Barit, L.N. Katsaurov, IM. Frnk, and I.V. Shuranith, Sov. J. Atomic Energy, Atomnaya Energiya, Supp. No. 5, 43 (1957); LN. Katsaurow, Aked. Nauk USSR, Trudy F12. Inst. 14, 224 (1962).

S.J. Brme, Jr. and J.E. Perry Jr., Ptys. Rev. 107, 1616 (195T).

JM. Blair, G. Freier, E. Lampi, W. Sleator, Jt., and J.H. Williams, Phys. Rev. 74, 1599 (1948).

T.W. Bower, J.P. Conner, and A.B. Lillie. Fhys. Rev. 89.473 (1952).

DI. Booth, G. Preston, and P.F.D. Shaw, Proc. R. Soc. London, Ser. A 69, 265 (1956).

E. Bretacber and A.P. French, Phys. Rev. 7S, 1154 (1949).

J.E Brolley, Jr., J.L. Fowler, and E.J. Stovall, Jr., Phys, Rev. 82, 502 (1951).

J.E. Brolley, Jr., T.M. Pumum. and L. Rosen, Phys. B.sv. 107, 820 (1957).

R.E. Brown, N. Jamie, and G.M. Hale, Phys. Rev. C 35, 1999 (1987).

R.E. Brown and N. Jamie, Los Alamos National Laboratory Report LA-UR-89-953; Phys. Rev. C 41, 1391 (1990).

R.F. Cartion, Ph. D. Thesis, University of Georgis (1970); private communication to N. Jamie (1978),

P.R. Chipon and G.E. Owen, Phys. Rev. 101, 1798 (1956).

J.P. Conner, T.W. Bonner, and J.R. Solith, Phys. Rev. 88, 468 (1952).

C.F. Coot and J.R. Smith, Phyk Rev. 89, 785 (1953).

W.W. Dechnick and J.M. Fowler, Phys, Rev. 111, 1309 (1958).

P.A. Devenport, T.O. Jeffies, M.E. Owen, F.V. Price, and D. Roaf, Proc. R. Soc. London, Ser. A 216, 66 (1953),

V.A. Davidenko, A.M Kucher, I.S. Pogrebor, and Iu.F. Tuturov, Sov. J. At. Energy, Suppl. 5, 7 (1957).

J.A. Davies and P.R. Norion, Nucl. Instrum. Methods 168, 611 (1980).

M. Drosg, Nuc. Sci. Eng. 67, 190 (1978); 2 Phys. A 300, 315 \{1981).

M.R. Dwarkanath, Ft D. Thesis, Califoria institue Tectrology (1969).

E.A. Elioh, D. Roaf, and P.F.D. Shaw, Proc. R. Soc. Londan, Ser. A 216, 57 (1953).

K.W. Erickson, J.L Fowler, and E.J. Stovill, Jr., Phyt. Rev. 75, 894 (1949); Phys. Rev. 761141 (1949).

G. Freier and H. Holmgen, Phys. Rev, 93, 825 (1954).

A. Galonsky and C.H. Johnson, Phys. Rev. 104, 421 (1956).

A.S. Gmeev, A.M. Govorov, G.M. Oeetinstai, A.N, Ratdimenko, LV. Sizov, and V.S. Siksin. Sov. J. AL. Energy, Suppl 5, 21 (1957).

M.D. Coldberg and J.M. Le Blanc, Phys. Rev. 119, 1992 (1960).

M.D. Goldberg and J.M. Le Blanx, Phys. Rev. 122, 164 (1961).

A.M. Govorov, Li Ka-Yeng, G.M, Osetinstii, V.I. Salatshii, and I.V. Sizov, Sov. Phys. JETP 15, 266 (1962).

A.C. Grves, E.R. Greves, J.H. Coon, and J.H. Manley, Phys. Rev, 70, 101 (1946).

W. Griebler, V. König, A. Ruh, P.A. Schmelzbach, RE. White, and P. Mamier, Nucl. Phys. A176, 631 (1971).

W. Gritebler, V. König, P.A. Schmelubach, R. Rjsler, R.E. White, and P. Marmier, Nucl. Phys. A193, 129 (1972).

A. Hemmendinger and H.V. Argo. Phys. Rev. 98, 70 (1955).

G.T. Hunter and H.T. Richards, Phys. Rev. 76, 1445 (1949).

N. Jamie and R.C. Allen. Fhys. Rev. 111, 1121 (1958).

N. Jamie, R.E. Brown, and R.A. Hadekopf, Phys. Rev. C 29, 2031 (1984).

N. Jamic and R.E Brown, Nucl. Instnum. Methods B 1011, 405 (1985); N. Jamie, private communication (1989).

R.G. Jarvis and D. Rouf, Proc. R. Soc. London, Ser. A 218, 432 (1953).

A.P. Kliucharew, B.N. Esel'son, and A.K. Val'ter, Sow. Phys. Dokledy 1, 475 (1950).

A.P. Kobzev, V.L Sulatski, and S.A. Teleahnikov, Sov. J. Nucl. Phys. 3, 774 (1966).

A. Krauss, H.W. Becker, H.P. Trautvetier, C. Rolfs; and K. Brand, Nucl Phys. A465, 150 (1987).

W.E. Kumz, Fbys. Rey. 97, 456 (1955), and Ph. D. Ithecis, Univerxity of Tennessee. (1954).

H.A. Leiter, R.E. Meagher, F.A. Rodges, and P.G. Kruger, Phys. Rev. 76, 167 (1949).

E. Magien, M Bormann, W. Scobel, and P. Heiss, Nucl. Phys. A246, 413 (1975).

J.H. Minjey, J.H. Coon, and E.R. Gruves, Phys. Rev. 70, 101 (1946).

D.K. McDaniels M Drosg, J.C. Hopkins, and J.D. Seagrave, Phys. Rev, C 7, 882 (1973).

K.G. MaNeill and G.M. Keyser, Phys. Rev. 11,602 (1951).

J. Moffut, D. Ronf, and J.H. Sanders, Proc. R. Soc. London, Ser, A 212, 220 (1952).

W. Moller and F. Besenbucher, Nucl. Instrum. Methods 168, 111 (1980).

A. Okihana, N. Fujiwan, H. Naknoun-Yokot, T. Yanabu, R. Fukunaga, T, Ohsawa, and S. Tanaka, J. of Phys.

Soc. Japan W6, 707 (1979).

G. Preston, P.F.D. Shaw, and S.A. Young, Proc. R. Soc. London, Ser. A 226, 206 (1954).

J.H. Sunders. J. Moffut, and D. Rouf, Foys. Rev. 77, 754 (1950).

R.L. Schulie, M. Cosack, A.W. Obst, and J.L. Weil, Nucl. Phys. A192, 609 (1972).

V.J. Serov, S.N. Abramovich, and LA. Morkin Sov. J. AL Energy 42, 66 (1977).

L. Stewar, J.E. Brolley, Jr., and L. Rosen, Phys. Rev. 119, 1649 (1960).

T.F. Struton and G.D. Freier, Phys. Rev. 88, 261 (1952).

Yu.V. Strel'nikov, S.N. Abramovich, L,A. Morkin, and N.D. Yur'eva, Bull. Acad. Sci. USSR Phys. Sci. (Isv.) 3S, 149 (1971).

S.T. Thomion, Nucl. Phys, A136, 25 (1969).

J.L. Tuck, W.R. Amold, J.A. Phillips, G.A. Sawyer, and E.J. Stovall. Jr., Phys. Rev. 88, 159A (1952).

A. Yon Engel and C.C. Goodyear, Proc. R. Soc. Loncon, Ser. A 264, 445 (1961).

W.A. Wenzel and W. Whaling, Phys. Rev, 88, 1149 (1952).

JL. Yamell, R.H, Lowberg, and W.R. Stuwon, Phys. Rev. 90,292 (1953). 